\title{
Hands Touching Hands: Affective and Evaluative Effects of an Interpersonal Touch*
}

JEFFREY D. FISHER

University of Connecticut

MARVIN RYTTING

RICHARD HESLIN

Purdue University

A 2 (touch-no touch) $\times 2$ (sex of confederate) $\times 2$ (sex of subject) between subjects design tested the affective and evaluative consequences of receiving an interpersonal touch in a Professional/Functional situation. It was found that the affective and evaluative response to touch was uniformly positive for females, who felt affectively more positive and evaluated the toucher and the environmental setting more favorably than in no touch conditions. The male response to touch was more ambivalent.

Academic interest in touch is evidenced by commentaries which have approached touch from theoretical and applied perspectives (Burton and Heller, 1964; Cashar and Dixson, 1967; Johnson, 1965; Kaufman, 1971; Montagu, 1971), and from a humanistic standpoint (Egan, 1970; Schutz, 1967, 1972; Watson, 1972). In addition, popular concern about touch is highlighted by the interest in recent books on human interaction which have dealt with touching (Davis, 1973; Fast, 1971; Morris, 1973).

In past experimental research, the effects of early tactile stimulation have been investigated with both human and animal young. In animal work on contact needs in young monkeys (Harlow, 1971) and on the effects of early handling, stimulation, and stress (Denenberg and Rosenberg, 1967; Denenberg and Whimbey, 1963; Levine, 1960), investigators have found that early contact and handling are beneficial, and even essential to the intellectual, emotional, and social growth of animals. The essential nature of early touching for human infants was first

\footnotetext{
*This research was supported in part by National Science Foundation Grant GS-40329 to Donn Byrne, and Grant GS-2893 to Richard Heslin. We would like to thank the staff of the Purdue University main library for permission to run this study, and for their support during the conduct of the research. The helpful comments of Paul Bell and Betsy Laughlin on an earlier draft of this manuscript are appreciated. Send reprint requests to Dr. Jeffrey Fisher, Department of Psychology, University of Connecticut, U-20, Storrs, Connecticut 06268.
}

established by Spitz (1946); more recent work with infants (Montagu, 1971; Morris, 1973) indicates that tactile stimulation is important for emotional, intellectual, and physiological development.

Studies which have been concerned with the effects of touch on adults, however, have found that touch may have either positive or negative effects. In terms of the potential positive effects, Aguilera (1967) found that touch increased verbalization and improved attitudes toward nurses among psychiatric patients; and Pattison (1973) reported that touch in counseling sessions precipitated self-disclosure on the part of clients. In addition, Bardeen (1971) found that subjects described an experimental confederate, with whom they interacted by means of touch, more positively than the same confederate in verbal only or visual only conditions; Geis and Viksne (1972) reported that subjects receiving and reciprocating back rubs experienced a drop in palmar sweat index.

As any man who has been slapped for "making a pass" can testify, however, the effect of touch is not always positive. In this regard a number of studies have shown that touch can fail to have positive effects, and may even have negative effects. For example, Walker (1971) reported that communicating by means of touch made subjects feel anxious and generally uncomfortable. In addition, in encounter group research, level of trust (Clarke, 1971) and empathy (Poaster, 1971) did not differ in touch and no touch conditions. 
The varying reactions to being touched observed in past studies may stem from the nature of touch: while the message of touch has an inherent ambiguity (Nguyen et al., 1975), touching usually has a fairly clear intentionality. In effect, touch implies that a communication is intended, but the content of the communication may not be clear. In general, it is assumed that touch is an essentially positive stimulus for the recipient to the extent that it does not: (a) impose a greater level of intimacy than the recipient desires (e.g., Argyle and Dean, 1965; Hall, 1963), or (b) communicate a negative message (e.g., be perceived as condescending or symbolic of the recipient's lower status; Henley, 1973).

The past research on favorableness of reactions to interpersonal touch has failed to consider the effect of an important source of tactile stimulation: no research has dealt with the effect of momentary tactile contacts between interacting strangers (e.g., clerks handing change to customers). The purpose of this study is to investigate the effect of such a touch for the recipient's affective state and evaluative responses. In addition to providing information about the affective consequences of one of the most common forms of tactile stimulation, the research will also investigate the effects of this type of touch on the recipients' evaluations of the toucher, and their evaluations of associated stimuli (i.e., the physical environment).

In the present experimental context, the manipulation of tactile contact between strangers consists of a library clerk touching an individual while in the process of handing back the person's library card. As with other tactile contacts between interacting strangers, the present touch has the potential of being perceived as intentional, and hence as meaningful. Further, it is not unduly intimate and does not lend itself to being interpreted as a negative message (Heslin, 1974a). Therefore,

$\rightarrow$ it was hypothesized that a momentary touch between interacting strangers would be experienced as a mildly pleasant stimulus, and that it would arouse positive affect. Further, $\rightarrow$ and in line with the Byrne-Clore (1970) prediction that affective state determines evaluation of associated stimuli, the affect precipitated by being touched was expected to generalize to elicit positive evaluations of the toucher and the environmental setting.

\section{METHOD}

One hundred and one students (52 males and 49 females) who were checking out books from a university library served as subjects. The prerequisite for inclusion in the study was that a potential subject be an undergraduate student who was alone as he or she approached the check-out counter. Each individual who met these criteria was included in the experiment. The experiment was conducted during weekday mornings, afternoons, and evenings.

A 2 (touch-no touch) $\times 2$ (sex of confederate) x 2 (sex of subject) betweensubjects design was employed in which each male and female subject was randomly assigned to the experimental conditions. ${ }^{1}$

For alternate half-hour periods, the library clerks either touched or did not touch each subject for whom they checked out books. In the no touch condition the clerk handed the subject's library card back without making physical contact with the individual's hand. For the touch condition, the library card was returned to the subjects in such a way that the clerk placed his or her hand directly over the individual's palm, making physical contact. This position was maintained for about half a second. ${ }^{2}$

${ }^{1}$ Three female clerks took part in the experiment. Since only one male clerk was employed by the library at the time the study was run, only one male clerk took part. However, after the study was completed, two additional male clerks who were employed by the library the following semester were asked to run forty "pilot" subjects. The purpose was to determine whether data from the first male clerk would be representative of male clerks in general. A comparison was made to determine if the responses they elicited differed from those elicited from the first male clerk. Analyses revealed that there were no differences between the three male clerks for any of the dependent measures used in the study. The intent in running the additional clerks was only to provide data to ascertain whether there were idiosyncratic qualities in the original male clerk which would render him non-comparable to other male clerks. It should be noted that it was anticipated beforehand that due to highly discrepant cell sizes which would be created (i.e., twice as many subjects in male clerk conditions as in female clerk conditions), it would be impossible to include subjects run with the additional clerks in the overall data analysis.

${ }^{2}$ Each of the clerks who served as experimental confederates was blind to the experimental hypotheses. Clerks were trained to behave in a uniform 
Upon completion of the librarian-subject interaction, the experimenter approached the subject, stated that the library was doing an evaluation of its personnel and facilities, and asked the subject if he or she could spare a few minutes to fill out some questionnaires. Subjects were informed that their responses would be kept confidential, and that ratings would have no negative repercussions for library employees. The refusal rate was minimal, with no differences in frequency between conditions. After a subject agreed to participate, he or she was taken to a private room and introduced to a second experimenter, who gave the individual a folder containing the dependent measures. After the scales were completed, this experimenter debriefed the subject as to the purpose of the experiment; post-experimental interviews revealed that none of the subjects expressed suspicion with respect to the role of the clerk.

\section{Dependent Measures}

Evaluation of affective state. A feelings scale similar to one previously established as a self-report measure of affect by Byrne and Clore (1970) and Griffitt (1970) was used as a measure of affect. ${ }^{3}$ This scale consists of five evaluative bipolar adjective pairs arranged as seven-point scales. Responses to the items (happy-sad, negative-positive, comfortableuncomfortable, bad-good, pleasant-unpleasant) are summed to yield a measure of affect along a positive-negative dimension ranging from 5 (most negative) to 35 (most positive).

Evaluation of library clerk. Four sevenpoint bipolar adjective items were included to measure the subject's evaluation of the clerk who had checked out the books. The four items-positive-negative, helpful-not helpful, good-bad, friendly-unfriendly-were all highly

manner in all experimental conditions and kept all aspects of their behavior (e.g., eye contact) constant, with the exception of touch. Independent ratings verified that this was the case. Further, independent ratings confirmed that each clerk was above average in physical appearance for a member of their respective sex.

${ }^{3}$ The present feelings scale differed from the one used by previous investigators in that the item "high-low" was omitted, due to the possibility of confusion on the part of subjects as to its interpretation. intercorrelated (above .50), and are summed to yield a single measure of evaluation of the clerk ranging from 4 (most negative) to 28 (most positive).

Evaluation of library environment. Four seven-point bipolar adjective items were included to measure the perceived positiveness of the library environment. The four items (positive-negative, attractive-unattractive, comfortable-uncomfortable, good-bad) tap a single aesthetic quality dimension as indicated by a principal components analysis (Fisher, 1973), and are summed to constitute an index of perceived positiveness of environmental quality ranging from 4 (most negative) to 28 (most positive).

\section{RESULTS}

A 2 (touch-no touch) $\times 2$ (sex of confederate) $\times 2$ (sex of subject) multivariate ANOVA was performed on the data, since three conceptually related dependent measures were used (Bock and Haggard, 1968). Parallel $2 \times 2 \times 2$ univariate ANOVAs were also run for each of the three dependent measures (Hummel and Sligo, 1971).

The multivariate ANOVA on all of the dependent measures revealed a significant main effect for touch $(F=3.452$, df $=3 / 91$, $\mathrm{p}<.02)$. This main effect was parallelled by univariate touch main effects for the measures of affective state evaluation $(\mathrm{F}=4.21$, $\mathrm{df}=$ $1 / 93, \mathrm{p}<.04)$, and library clerk evaluation ( $\mathrm{F}$ $=6.02$, df $=1 / 93, \mathrm{p}<.02)$. The touch main effect for affective state evaluation indicated that more positive affect was experienced by subjects who were touched (27.9) than by those who were not touched (25.7): For the library clerk evaluation, the touch main effect indicates that subjects who were touched rated the clerk significantly more favorably (23.4) than those who were not touched (21.1).

The multivariate ANOVA also revealed a trend towards a touch by sex of subject interaction $(\mathrm{F}=1.90, \mathrm{df}=3 / 91, \mathrm{p}=.13)$. This interaction was paralleled by weak touch by sex of subject interactions for the measures of affective state evaluation $(\mathrm{F}=2.69, \mathrm{df}=1 / 93$, $\mathrm{p}<.10)$ and library clerk evaluation $(\mathrm{F}=$ 3.28 , df $=1 / 93, \mathrm{p}<.07)$, as well as a significant touch by sex of subject interaction for the measure of library environment evaluation $(F=4.76$, df $=1 / 93, p<.03)$. 
Overall, the univariate interactions between touch and sex of subject suggest that the more positive affect observed in touch conditions was accounted for mainly by the response of female subjects. (See Tables 1, 2, and 3 for the results of Newman-Keuls multiple range tests performed on the univariate interaction means for each of the three dependent measures).

TABLE 1

Positiveness of Affective State

\begin{tabular}{lll}
\hline \hline & \multicolumn{2}{c}{ Sex of Subject } \\
\cline { 2 - 3 } Condition & Male & Female \\
\hline Touch & $26.1^{\mathrm{b}}$ & $29.7^{\mathrm{a}}$ \\
No touch & $25.6^{\mathrm{b}}$ & $25.8^{\mathrm{b}}$ \\
\hline
\end{tabular}

Note: Means with common superscripts do not differ at the .05 level as indicated by the Newman-Keuls procedure.

TABLE 2

Positiveness of Library Clerk Evaluation

\begin{tabular}{lll}
\hline \multirow{2}{*}{ Condition } & \multicolumn{2}{c}{ Sex of Subject } \\
\cline { 2 - 3 } Touch & Male & Female \\
No touch & $22.3^{\mathrm{a}, \mathrm{b}}$ & $24.5^{\mathrm{b}}$ \\
\hline
\end{tabular}

Note: Means with common superscripts do not differ at the .05 level as indicated by the Newman-Keuls procedure.

TABLE 3

Positiveness of Library Environment Evaluation

\begin{tabular}{llc}
\hline \multirow{2}{*}{ Condition } & \multicolumn{2}{c}{ Sex of Subject } \\
\cline { 2 - 3 } & Male & Female \\
\hline Touch & 15.6 & 17.6 \\
No touch & 18.7 & 15.7 \\
\hline
\end{tabular}

To determine whether the effect of touch is dependent upon conscious perception of the touch stimulus, subjects in touch conditions were asked during the debriefing if they had perceived the touch by the library clerk. Only 57\% indicated that they had. To assess the possibility that the responses of subjects who were aware of the touch differed from the responses of those who indicated no such awareness, for each of the dependent measures $t$-tests were run to test the differences between the means for the two groups. No differences between the "aware" and the "unaware" groups were found for any of the dependent measures. Thus, the effect of being touched was evidenced even when the touch apparently was not perceived.

\section{DISCUSSION}

As hypothesized, a casual touch of a very short duration in a Professional/Functional situation had positive consequences for the recipient. The multivariate analysis of the dependent measures revealed a main effect for touch, which indicated that subjects in touch conditions evidenced more positive responses than subjects in no touch conditions. Further, a trend toward a multivariate interaction between touch and sex of subject suggests that while the response to the touch condition was uniformly positive for females, it was more ambivalent for males. This fits well with the previous finding that females touch and are touched by significant others more than males, and that within any relationship, females report being touched more than touching (Jourard, 1966). It is suggested that females, who have had more experience as recipients of touch from significant others, may be more comfortable than males when receiving momentary interpersonal touches from strangers. In effect, for females, the touch employed in this study acts as a "Midas" touch which affects the recipient positively both in terms of personal feelings and in terms of evaluation of the environment.

The failure to observe any effects for sex of the toucher in the present experiment was at first surprising. That these findings were not due to idiosyncratic qualities of a single male clerk is evidenced by the results of an analysis which compared those subjects run by the original male clerk to subjects run later by additional male clerks (see footnote 1). Hence, the explanation for the failure to find effects for the sex of the toucher may lie in the quality of the Professional/Functional touching situation employed in the present study. Considering the asocial and asexual nature of the relationship between a clerk and 
an individual checking out books, the impact of the touch manipulation on the subjects may have been limited to that of a touch from a clerk whose sexual identification was not particularly relevant. It might be expected that in a more social situation the sex of the toucher would have a more powerful effect on the recipient of the touch.

A potentially important finding of the present study was that touch recipients who were not consciously aware of being touched did not differ significantly on any of the dependent measures from those who were aware of being touched. Thus, whether or not the touch was perceived, it generally had a positive effect on the recipient's responses. There are several potential alternative explanations for this finding. First, there is a possibility that subjects who reported that they were not touched distorted their report rather than their perception, but observation of these respondents yielded no indication of why they would withhold such information. A second possibility, that the subjects who reported they did not perceive the touch, were not in fact touched, is not tenable because independent observers confirmed that the touch was made. A third alternative explanation is that the individuals who failed to perceive the touch are people who customarily receive so many touches that being touched does not represent a significant occurrence to them, and consequently, they did not notice the manipulation.

It is our contention, however, that the best explanation for failure to perceive the touch manipulation is that the touch employed in this experiment was so minimal as to be hardly noticed by the recipients. If this is the case, then the potency of the act of touching another person becomes very striking: a touch of less than one second has the power to make people feel better, and this effect can generalize to evaluation of associated stimuli. The observed relationship between affective response to touch and subsequent evaluative judgments of associated stimuli is generally in accord with the prediction of the Byrne and Clore (1970) reinforcement-affect model of evaluative responses. In terms of the model, the affect induced by touch is conceptualized as mediating subsequent evaluative responses to associated stimulus objects (i.e., evaluations of the clerk and the library environment).

Finally, to some extent, previous research on the effects of touch has been hampered by lack of appropriate methodology (Heslin, 1974b). The present study demonstrates a means of studying the effect of touch, under experimental control, yet in a real world setting which is not likely to cause unnatural behavior on the part of participants.

\section{REFERENCES}

Aguilera, D. C.

1967 "Relationships between physical contact and verbal interaction in nurses and patients." Journal of Psychiatric Nursing 5:5-21.

Argyle, M. and J. Dean

1965 "Eye contact, distance, and affiliation." Sociometry 28:289-304.

Bardeen, J. P.

1971 "Interpersonal perception through the tactile, verbal, and visual modes." Paper presented at the Meeting of the International Communication Association, Phoenix, Arizona (April).

Bock, R. D. and E. A. Haggard

1968 "The use of multivariate analysis of variance in behavioral research." In D. K. Whitla (ed.), Handbook of Measurement and Assessment in Behavioral Sciences. Reading, Massachusetts: Addison-Wesley.

Burton, A. and L. G. Heller

1964 "The touching of the body." Psychoanalytic Review 51:122-134.

Byrne, D. and C. L. Clore

1970 "A reinforcement model of evaluative responses." Personality: An International Journal 1:103-128.

Cashar, L. and B. K. Dixson

1967 "The therapeutic use of touch." Journal of Psychiatric Nursing 5:442-451.

Clarke, J. F.

1971 "Some effects of nonverbal activities and group discussion on interpersonal trust development in small groups." Doctoral dissertation, Arizona State University. Ann Arbor, Mich.: University Microfilms No. 71-18, 955.

Davis, F. (ed.)

1973 Inside Intuition: What We Know About Nonverbal Communication. New York: McGraw-Hill.

Denenberg, V. H. and K. M. Rosenberg

1967 "Nongenetic transmission of information." Nature 216:549-550.

Denenberg, V. H. and A. E. Whimbey

1963 "Behavior of adult rats is modified by the experiences their mothers had as infants." Science 142:1192-1193.

Egan, G. (ed.)

1970 Encounter: Group Processes for Interpersonal Growth. Belmont, California: Brooks/Cole Publishing Company.

Fast, J. (ed.)

1971 Body Language. New York: Pocket Books. 
Fisher, J. D.

1973 "Attitude similarity as a determinant of perceived crowdedness and perceived environmental quality: Support for an interactive model for prediction of the behavioral effects of density and other environmental stimuli." Unpublished master's thesis, Purdue University.

Geis, F. and V. Viksne

1972 "Touching: Physical contact and level of arousal." Proceedings of the Annual Convention of the American Psychological Association 7:179-180.

Griffitt, W.

1970 "Environmental effects on interpersonal affective behavior: Ambient effective temperature and attraction." Journal of Personality and Social Psychology 15:240-244.

Hall, E. T.

1963 "A system for the notation of proxemic behavior." American Anthropologist 65:1003-26.

Harlow, H. (ed.)

1971 Learning to Love. New York: Albion Publishing Co.

Henley, N. M.

1973 "The politics of touch." In P. Brown (ed.), Radical Psychology, New York: Harper and Row.

Heslin, R.

1974a "Steps toward a taxonomy of touching." In R. Heslin (chm.), Getting Close: Research and Theory on Spatial Distance, Touching, and Eye Contact. Symposium presented at the Midwestern Psychological Association, Chicago (May).

$1974 \mathrm{~b}$ "The use of nonverbal behavior in patient care." Unpublished manuscript. Purdue University.

Hummel, D. and E. Sligo

1971 "Comparing multivariate and univariate analysis of variance." Psychological Bulletin 76:49-57.

Johnson, B. S. 1965 "The meaning of touch in nursing." Jourard, S. M.

1966 "An exploratory study of body-accessibility." British Journal of Social and Clinical Psychology 5:221-231.
Kaufman, L. E.

1971 "Tacesics, the study of touch: A model for proxemic analysis." Semiotica 4:149-161.

Levine, $\mathrm{S}$.

1960 "Stimulation in infancy." Scientific American 202:80-86.

Montagu, A. (ed.)

1971 Touching: The Significance of the Human Skin. New York: Columbia University Press.

Morris, D. (ed.)

1973 Intimate Behavior. New York: Bantam Books.

Nguyen, T. R., R. Heslin, and M. L. Nguyen

1975 "The meaning of touch: Sex differences." Journal of Communication 25:92-103.

Pattison, J. E.

1973 "Effects of touch on self-exploration and the therapeutic relationship." Journal of Consulting and Clinical Psychology 40:170-175.

Poaster, L. B.

1971 "A comparison of different modes of communication and their effects on attitude change and the development of empathy." Doctoral dissertation, University of Tennessee. Ann Arbor, Mich.: University Microfilms, No. 71-7669.

Schutz, W. C. (ed.)

1967 Joy. New York: Grover Press

1972 Here Comes Everybody. New York: Harper and Row.

Spitz, R. A.

1947 "Hospitalism." The Psychoanalytic Study of the Child. 2:113-117.

Walker, D. N.

1971 "Openness to touching: A study of strangers in nonverbal interaction." Doctoral dissertation, University of Connecticut. Ann Arbor, Mich.: University Micro-

Watson, G. films, No. 71-18, 454.

1972 "Nonverbal activities: Why? When? How?" In W. G. Dyer (ed.), Modern Theory and Method in Group Training, New York: Van Nostrand Reinhold Co.

Winer, B. J. (ed.)

1971 Statistical Principles in Experimental Design. New York: McGraw-Hill. 
Copyright of Sociometry is the property of American Sociological Association. The copyright in an individual article may be maintained by the author in certain cases. Content may not be copied or emailed to multiple sites or posted to a listserv without the copyright holder's express written permission. However, users may print, download, or email articles for individual use. 